\title{
Is Low Hemoglobin Level a Risk Factor for Acute Lower Respiratory Tract Infections?
}

\author{
Malla ${ }^{1}$, Pathak OK${ }^{2}$, Malla $\mathrm{KK}^{3}$ \\ ${ }^{1}$ Dr. Tejesh Malla, MBBS, MD, Assistant Professor, ${ }^{2}$ Dr. Om K Pathak, MBBS, Medical Officer, ${ }^{3}$ Dr. Kalpana K Malla, MBBS, \\ MD, Associate Professor. All from the Department of Paediatrics, Manipal College of Medical Sciences, Pokhara, Nepal.
}

Address for correspondence: Dr. Tejesh Malla, E-mail: tejeshmalla@hotmail.com

\begin{abstract}
Objective: This prospective study was conducted to evaluate whether a low hemoglobin level, was a risk factor for Acute Lower Respiratory Tract Infections (ALRTI) in children. Methods: 150 Children of all age groups who came to the outpatient department and those admitted for ALRTI were included in the study. Age and sex-matched 140 children, not having any respiratory illness, were taken as control. The study period was from March 2006 - March 2007. Detailed clinical and laboratory evaluation of the enlisted patients was done. All were subjected to detail investigations. Results: Radiological evidence of pneumonia was present in $70(50 \%)$ children. Hyperinflated lungs were seen in $40(29 \%)$ and was normal in $30(21.4 \%)$ cases. Blood culture was positive in $14(10 \%)$ children of study group and none among control group. Klebsiella was the commonest organism isolated $6(4.2 \%)$ in blood culture positive cases. The mean Hemoglobin $(\mathrm{Hb})$ level of study group was $9.88 \mathrm{gm} \%$ and it was $12 \mathrm{gm} \%$ in control group.96 $(68.6 \%)$ of study group and $30(21.42 \%)$ of control group had anemia. Of the anemic children, $79(82.3 \%)$ in study group had iron deficiency, and $17(17.7 \%)$ had normocytic normochromic anemia. These values were $18(33.3 \%)$ and $36(66.6 \%)$ respectively for control group. Low hemoglobin level was a risk factor $(p<0.001)$ ALRTI. Conclusion: Anemic children were 3.2 times more susceptible to ALRTI compared to the control group and and iron deficiency anemia was predominating. Supplemental iron therapy may reduce the incidence of ALRTI. Prevention of anemia, due to whatever etiology is also essential.
\end{abstract}

Key words: ALRTI, anemia, hemoglobin.

\section{Introduction}

$A^{n}$ nemia is a major nutritional global problem of mmense public health significance, affecting persons of all ages, sex and economic group. It is ranked as the commonest chronic malady of mankind affecting approximately $30 \%$ i.e. 1500 million people all over the world. Iron deficiency anemia in children occurs most frequently between the age of 6 months to 3 years ${ }^{1}$, the age when repeated infection occurs. On an average, children below 5 years of age suffer about 5- 6 episodes of ALRTI per year ${ }^{2}$. With this view the present study was conducted to see if children with iron deficiency anemia were at higher risk of ALRTI.

\section{Methods}

This prospective study was carried out for a period of one year from March 2006 - March 2007 in pediatric department of Manipal Teaching Hospital, Pokhara. A total of 290 (150 cases and140 controls) children from 1 month to 5 years of age attending out patient department and those hospitalized were studied. Controls were age and sex matched children not having respiratory problems. The inclusion criteria for cases were children with fever, cough, and fast respiratory rate, chest indrawing as per $\mathrm{WHO}$ criteria, and ronchi or crepitations on auscultation. The exclusion criteria was children suffering from other systemic illnesses like 
Congenital heart disease, tuberculosis (any evidence plus Montaux test positive cases) and Protein Energy Malnutrition (PEM > Grade III as per Indian Academy of Pediatrics (IAP) classification). Children who already received antibiotic from outside were also excluded from the study. The purpose of the study was explained to the parents or guardians. Then consent was taken from parents or guardians before they were subjected to investigations. The investigations in both case and control included; complete blood count (CBC) with a peripheral smear, blood culture and sensitivity test, and $\mathrm{X}$-ray chest, serum iron and serum iron binding capacity. Serumferritin level was not done. Syanmeth method by colorimeter was used to identify $\mathrm{Hb}$ level. Hemglobin level $<10 \mathrm{gm} \%$ will be considered low in this study. Data were analysed using SPSS 10.0 by logistic multinomial regression analysis.

\section{Results}

Out of 290 children 150 were cases among which 10 were Mantoux positive hence was excluded from the study. Therefore the final figure was 140 (99 males and 41 females) cases and 140 (94 males and 46 females) controls. Among the cases 10 (8 males and 2 females) were less than 2 months, 69 (43 M and 26 F) were inbetween 2 months -1 year and 61 ( $48 \mathrm{M}$ and $13 \mathrm{~F}$ ) were above 1 year. Similarly for control group the distribution was $10(6 \mathrm{M} / 4 \mathrm{~F}), 50(30 \mathrm{M} / 20 \mathrm{~F})$, and 80 $(58 \mathrm{M} / 22 \mathrm{~F})$ were $\leq 2$ months, 2 mo-1year and $>1$ year respectively. (Table1). Fever, cough and shortness of breath was main clinical features in the cases whereas fever, pain abdomen diarrhea, vomiting, seizures was main clinical features in the control group (Table 2). Radiological evidence of pneumonia was present in 70 (50\%) children, hyperinflated lungs in 40 (29\%) cases and normal in $30(21.4 \%)$ cases (Fig 1). Out of 40 children who had hyperinflated lung fields 20 (50\%) had a history of recurrent wheeze ( fig.2) and 10 ( 25\%) gave a positive family history of asthma. Blood culture was positive in $14(10 \%)$ children of study group (Table 3 ) and none among control group. Among the culture positives klebsiella was isolated in $6(4.2 \%)$, and growth of staphylococcus, streptococcus pneumoniea, acintobacter and E.coli was noted in $2(1.43 \%)$ cases each. The mean $\mathrm{Hb}$ level of study group was $9.88 \mathrm{gm} \%$ and it was $12 \mathrm{gm} \%$ in control group.96 (68.6\%) of study group and $30(21.42 \%)$ of control group had anemia. Of the anemic children, 79(82.3\%) in study group had iron deficiency, with mean MCV 64 (fl),Mean $\mathrm{MCH}$ 17pg,MCHC 25gm/dl,Mean S. Iron 35 $\mathrm{g} / \mathrm{dL}$,Mean TIBC $390 \mu \mathrm{g} / \mathrm{dL} .17(17.7 \%)$ had normocytic normochromic anemia. These values were 18 (33.3\%) [With mean MCV 68.7 (fl), Mean $\mathrm{MCH}$ 15pg, Mean MCHC 27gm/dl, Mean S. Iron $35 \mu \mathrm{g} / \mathrm{dL}$, Mean TIBC $350 \mu \mathrm{g} / \mathrm{dL}$ ] and $36(66.6 \%)$ respectively for control group (Table 4). There were 72 cases of bronchopneumonia among which 62 (86\%) of them were anemic whereas rest 68 were wheeze associated ALRTI (bronchiolitis \& recurrent wheeze ) of which 34 (50\%) were anemic.(Table 5). Descriptive data regarding multivariate logistic regression analysis showing the risk factor of ALRTI. Table 7 reveals the montaux positive cases which were excluded from the study.

Table 1: Age and Sex distribution of cases and control

\begin{tabular}{|c|c|c|c|c|}
\hline \multirow{2}{*}{ Sex } & \multicolumn{3}{|c|}{ Age } & \multirow{2}{*}{ Total } \\
\hline & $\leq 2$ months & $>2 \mathrm{mo}-1 \mathrm{yr}$ & $>1-5$ year & \\
\hline \multirow{3}{*}{$\begin{array}{l}\text { Case } \\
\text { Male=99 }(70.7 \%) \\
\text { Female=41(29.3\%) }\end{array}$} & & & & \multirow{3}{*}{140} \\
\hline & 8 & 43 & 48 & \\
\hline & 2 & 26 & 13 & \\
\hline Total & 10 & 69 & 61 & 140 \\
\hline \multirow{3}{*}{$\begin{array}{l}\text { Control: } \\
\text { Male= } 94(67 \%) \\
\text { Female=46 }(32.8 \%)\end{array}$} & & & & \multirow{3}{*}{140} \\
\hline & 6 & 30 & 58 & \\
\hline & 4 & 20 & 22 & \\
\hline Total & 10 & 50 & 80 & 140 \\
\hline
\end{tabular}


Table 2: Symptoms and signs at presentation

\begin{tabular}{|c|c|c|c|c|}
\hline \multirow{2}{*}{ Symptoms } & \multicolumn{2}{|c|}{ Case } & \multicolumn{2}{|c|}{ Control } \\
\hline & $N(n=140)$ & Percentage & $N(n=140)$ & Percentage \\
\hline Fever & 135 & $96.42 \%$ & 114 & $81.42 \%$ \\
\hline Cough & 140 & $100 \%$ & 8 & $5.71 \%$ \\
\hline Shortness of breath & 81 & $57.85 \%$ & 4 & $2.85 \%$ \\
\hline Convulsion & 10 & $7.14 \%$ & 30 & $21.42 \%$ \\
\hline Vomiting & 29 & $20.71 \%$ & 77 & $55 \%$ \\
\hline Diarrhea & 10 & $7.14 \%$ & 52 & $37.14 \%$ \\
\hline Noisy breathing & 50 & $35.71 \%$ & 0 & $0 \%$ \\
\hline Poor feeding & 80 & $57.14 \%$ & 60 & $42.85 \%$ \\
\hline Chest pain & 4 & $2.85 \%$ & 0 & $0 \%$ \\
\hline Irritable & 20 & $14.28 \%$ & 30 & $21.42 \%$ \\
\hline Fast breathing & 100 & $71.42 \%$ & 0 & $0 \%$ \\
\hline Delayed development & 0 & $0 \%$ & 6 & $4.28 \%$ \\
\hline Headache & 0 & $0 \%$ & 2 & $1.42 \%$ \\
\hline Pain abdomen & 0 & $0 \%$ & 35 & $25 \%$ \\
\hline Sore throat & 0 & $0 \%$ & 24 & $17 \%$ \\
\hline \multicolumn{5}{|l|}{ Signs } \\
\hline Chest indrawings & 120 & $85.71 \%$ & 0 & $0 \%$ \\
\hline Ronchi & 70 & $50 \%$ & 0 & $0 \%$ \\
\hline Crepitations & 60 & $42.85 \%$ & 0 & $0 \%$ \\
\hline Pyoderma & 0 & $0 \%$ & 4 & $2.85 \%$ \\
\hline Dehydration & 5 & $3.57 \%$ & 35 & $25 \%$ \\
\hline
\end{tabular}

Table 3: Blood culture of cases and control

\begin{tabular}{|l|c|c|c|c|}
\hline & \multicolumn{2}{|c|}{ Case $(\mathbf{n = 1 4 0 )}$} & \multicolumn{2}{c|}{ Control $(\mathbf{n = 1 4 0 )}$} \\
\hline Blood culture & Number & Percentage & Number & Percentage \\
\hline No growth & 126 & $90 \%$ & 140 & $100 \%$ \\
Growth & 14 & $10 \%$ & 0 & 0 \\
Klebsiella & 6 & $4.2 \%$ & & \\
Staphylococcus & 2 & $1.43 \%$ & & \\
S. Pneumniea & 2 & $1.43 \%$ & & \\
Acintobacter & 2 & $1.43 \%$ & & \\
E.coli & 2 & $1.43 \%$ & & \\
\hline
\end{tabular}

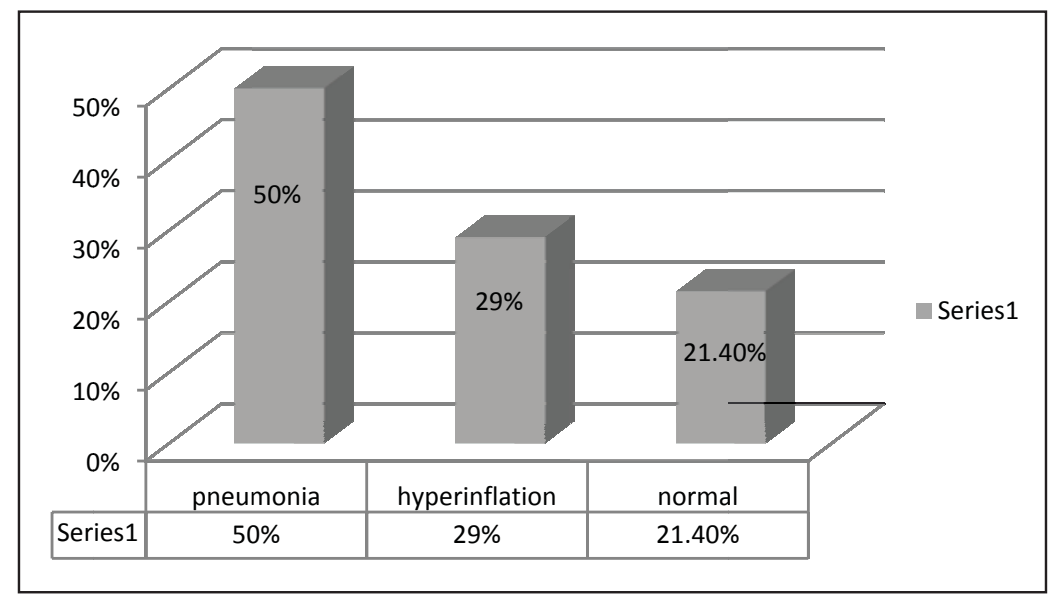

Fig. 1: Radiological findings of cases 


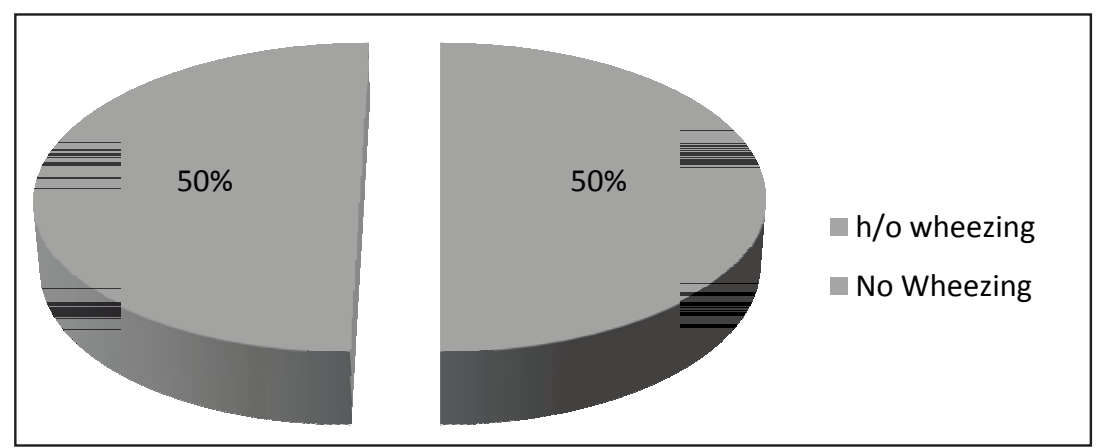

Fig. 2: Histrory of wheezing

Table 4: Hemogram of Cases and Control.

\begin{tabular}{|c|c|c|c|c|}
\hline \multirow[b]{2}{*}{ Hemoglobin } & \multicolumn{2}{|c|}{ Case $(n=140)$} & \multicolumn{2}{|c|}{ Control $(n=140)$} \\
\hline & Number & Percentage & Number & Percentage \\
\hline Mean $\mathrm{Hb}$ & $9.88 \mathrm{gm} \%$ & & $12 \mathrm{gm} \%$ & \\
\hline $\begin{array}{l}\text { Hemoglobin } \\
\leq 10 \mathrm{gm} \% \pm \\
>10 \mathrm{gm} \%\end{array}$ & $\begin{array}{l}96 \\
44\end{array}$ & $\begin{array}{c}68.6 \%) \\
31.4 \%\end{array}$ & $\begin{array}{l}54 \\
86\end{array}$ & $\begin{array}{l}38.6 \% \\
61.4 \%\end{array}$ \\
\hline $\begin{array}{l}\text { Anemia type } \\
\mathrm{MH}^{*} \\
\mathrm{NN}^{* *}\end{array}$ & $\begin{array}{l}79 \\
17\end{array}$ & $\begin{array}{l}82.3 \% \\
17.7 \%\end{array}$ & $\begin{array}{l}18 \\
36\end{array}$ & $\begin{array}{l}33.3 \% \\
66.6 \%\end{array}$ \\
\hline & MH anemia & NN anemia & MH anemia & NN anemia \\
\hline Mean $\operatorname{MCV}(\mathrm{fl})^{\star * *}$ & 64 & 80 & 68.7 & 79 \\
\hline Mean $\mathrm{MCH}(\mathrm{pg})^{\star * * *}$ & 17 & 25 & 15 & 27 \\
\hline Mean $\mathrm{MCHC}(\mathrm{gm} / \mathrm{dl})^{\star * * * *}$ & 25 & 32 & 27 & 34 \\
\hline S. Iron & $35 \mu \mathrm{g} / \mathrm{dL}$ & 95 & $35 \mu \mathrm{g} / \mathrm{dL}$ & 100 \\
\hline Mean $\mathrm{TIBC}^{+}$ & $390 \mu \mathrm{g} / \mathrm{dL}$ & 268 & $350 \mu \mathrm{g} / \mathrm{dL}$ & 270 \\
\hline
\end{tabular}

Note : Anemic $\pm=H b<10 \mathrm{gm} / \mathrm{dl}(\mathrm{Normal} \mathrm{Hb} \text { in }<2 \mathrm{mo} 9-14 \mathrm{gm} / \mathrm{dl} \text { and }>2 \text { months } 11.5-15.5 \mathrm{gm} / \mathrm{dl})^{3} \mathrm{MH}^{*}=$ Microcytic Hypochromic, $N^{* *}=$ Normocytic Normochromic, $\mathrm{MCV}^{* * *}=$ Mean Corpuscular Volume $(1 \mathrm{month}-6$ yrs $=76-$ $88(f I),{ }^{4} \mathrm{MCH}^{* * * *}=$ Mean Corpuscular Hemoglobin ( 1month- 6 yrs $=24-30$ (pg ), ${ }^{4} \mathrm{MCHC}^{* * * * *}=$ Mean corpuscular Hemoglobin Concentration ( 1month- 6 yrs $=30-36 \mathrm{gm} / \mathrm{dl}$ ), ${ }^{4}$ S.Iron (infants $=100-400 \mu \mathrm{g} / \mathrm{dL}$ and above Infancy $=250-400$ $\mu \mathrm{g} / \mathrm{dL})^{3}, \mathrm{TIBC}^{+}$-Total Iron Binding Capacity (all age $\left.=22-184 \mu \mathrm{g} / \mathrm{dL}\right)^{3}$

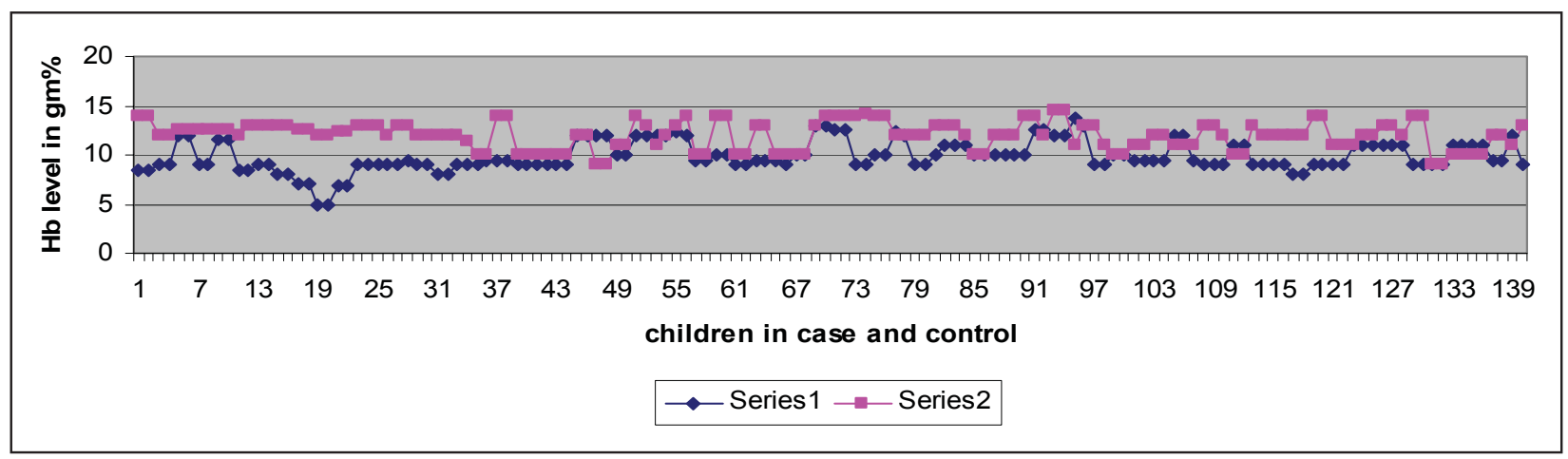

Fig. 3: Graph showing range of $\mathrm{Hb}$ in case and control 
Table 5: Low Hemoglobin with type of ALRTI

\begin{tabular}{|l|c|c|c|c|}
\hline \multirow{2}{*}{} & \multicolumn{2}{|c|}{ Bronchopneumonia (N= 72) } & \multicolumn{2}{c|}{$\begin{array}{c}\text { Wheeze associated LRTI bronchiolitis I } \\
\text { recurrent wheezing (N= - 68 ) }\end{array}$} \\
\cline { 2 - 5 } & Number & percentage & Number & percentage \\
\hline Hemoglobin & & & & $50 \%$ \\
$\leq 10 \mathrm{gm} \%$ & 62 & $86.0 \%$ & 34 & $50 \%$ \\
$>10 \mathrm{gm} \%$ & 10 & $13.9 \%$ & 34 & $\mathbf{1 0 0 \%}$ \\
\hline Total =140 & $\mathbf{7 2}$ & $\mathbf{1 0 0 \%}$ & $\mathbf{6 8}$ & \\
\hline
\end{tabular}

Table 6: Multivariate Logistic Regression Analysis Showing the Risk factor of ALRTI

\begin{tabular}{|l|c|c|c|}
\hline Parameters & OR & $95 \% \mathbf{C l}$ & Significance \\
\hline $\mathrm{HB} \leq 10$ & 5.6 & $2.7-11.7$ & $\mathrm{df}=1, \mathrm{p}<0.001$ \\
\hline S.Iron & 15.6 & $8.2-29.6$ & $\mathrm{df}=1, \mathrm{p}<0.001$ \\
\hline TIBC & 1.7 & $0.86-3.4$ & $\mathrm{df}=1, \mathrm{p}=0.119$ \\
\hline
\end{tabular}

C.I: Confidence interval, OR: Odds Ratio,df:degree of freedom, LRTI- Lower Respiratory Tract Infection.

Table 7: History, Clinical finding and CXR of Mantoux positive cases.

\begin{tabular}{|l|c|c|c|c|c|c|c|c|c|c|}
\hline Cases with Mantoux positive & $\mathbf{1}$ & $\mathbf{2}$ & $\mathbf{3}$ & $\mathbf{4}$ & $\mathbf{5}$ & $\mathbf{6}$ & $\mathbf{7}$ & $\mathbf{8}$ & $\mathbf{9}$ & $\mathbf{1 0}$ \\
\hline Recurrent ARI & + & + & - & + & - & + & + & + & + & + \\
\hline ESR $>50 \mathrm{~mm} / 1^{\text {st }} \mathrm{hr}$ & + & + & + & + & + & + & + & + & + & + \\
\hline Contact with TB & - & - & + & + & + & - & - & - & + & - \\
\hline Weight loss & + & + & + & + & - & - & + & + & + & + \\
\hline CXR - compatible with tuberculosis & + & + & - & - & - & - & - & - & + & + \\
\hline Gastric lavage for AFB & - & - & - & - & - & - & - & - & - & - \\
\hline Crofton, Horne and Miller scoring $>7$ & 9 & 9 & 8 & 10 & 8 & 7 & 8 & 9 & 9 & 8 \\
\hline
\end{tabular}

\section{Discussion}

Acute lower Respiratory tract infection (ALRTI) is a leading cause of mortality in children below 5 years of age in developing countries ${ }^{5}$. Hence it is important to control the risk factors to prevent deaths from ALRTI. Along with many risk factors like low birth weight, lack of breast feeding, severe malnutrition, smoke, cooking fuel $^{6}$, low hemoglobin may also be a risk factor. Present study was carried out to prove this fact.There were 140 cases $(M=99 \& F=41)$ and 140 controls $(M=94 \& F=46)$ among which in cases maximum children were between 2 month - 1 year.This signifies that ALRTI is most common in age group 2 month to 1 year. This is the time when a child starts having low hemoglobin levels and also this is the period of adding supplemental feed which may be inadequate and inappropritate. The reasons for higher number of males may be gender biasness by the parents to bring them for hospital care. Sign symptoms of patient had usual presentation of ALRTI. These patients came to us only after 4-5 days of illness or when the child became more ill as with less illness people of this region do not visit hospital. Radiologically evidence of pneumonia was higher 70 (50 \%) than hyperinflated lungs (bronchiolitis, recurrent wheeze) 40 (29\%).This may indicate that low hemoglobin has higher risk for pneumonia than bronchiolitis. Table 5 reveals that among pneumomia cases $86 \%$ were anemic whereas only $50 \%$ cases were anemic among bronchiolitis cases.There was no specific golden criterion to differentiate bacterial (pneumonia) or viral (bronchiolitis) ALRTI but ill looking child, CRP positive,neutrophilic leukocytosis,blood culture positive was considred bacterial infection and viral infection were assessed clinically and leucopenia was considered. Literature related to this finding was not available. It was observed that $20(50 \%)$ children with hyperinflated lung fields had a history of wheeze and 10 ( $25 \%$ ) gave a positive family history of asthma. This maybe due to the fact that bronchiolitis is more prone to occur if there is a genetic predisposition or has a history of Atopy rather than low hemoglobin. These population was not excluded from the study as they had features of secondary infection clinically with high fever, ill looking, not feeding well and biochemically with either neutrophilic leukocytosis or CRP positive. Blood culture showed growth in only $10 \%$ of cases and klebsiella was most common $(4.2 \%)$ organism isolated. In this study $\mathrm{Hb} \leq 10 \mathrm{gm} / \mathrm{dl}$ was considered anemia (Normal $\mathrm{Hb}=$ 
$<2$ mo $9-14 \mathrm{gm} / \mathrm{dl}$ and $>2$ months $-11.5-15.5 \mathrm{gm} / \mathrm{dl})^{3}$. Mean $\mathrm{Hb}$ level in this study was $9.58 \mathrm{gm} \%$ for cases \&12gm\% for Control group. Ramakrishnan K, Harish PS in their study found that anemic children were 5.75 times more susceptible to $\mathrm{LRTI}^{7}$ which was 3.2 times in this study. Several risk factors for developing ALRTI had been reported in different studies. Baskaran et al ${ }^{8}$ in their study in children between 3-5 years had found $83 \%$ with pneumonia had hemoglobin less than $11 \mathrm{~g} / \mathrm{dL}$. In this study microcytic and hypochromic picture was seen in maximum children (82.3\%). In another study of iron deficiency anemia and respiratory infection by De-Silva A et $\mathrm{al}^{9}$, an over all prevalence of anemia was found in $52.6 \%$. The role of low hemoglobin level per se, as a risk factor for developing ALRTI are reported only in few literatures ${ }^{7}$. They had found that reduced hemoglobin level due to whatever etiology was a significant risk factor for developing ALRTI. Unlike those studies here it was found that low hemoglobin due to Iron deficiency anemia was the main cause for ALRTI. Iron deficiency anemia was detected based on low MCV(normal=76-88 fl), low MCH(Normal=24-30 pg ), low MCHC(Normal=30$36 \mathrm{gm} / \mathrm{dl}$ ), low S.Iron [Normal=infants 100-400 $\mu \mathrm{g} / \mathrm{dL}$ and above Infancy 250-400 $\mu \mathrm{g} / \mathrm{dL}]$ and increased TIBC[ Normal $=$ all age $=22-184 \mu \mathrm{g} / \mathrm{dL}$ ]. Serum ferritin level was not done due to unavailability of this test and ferritin level is not reliable in cases with infection as it increases probably as acute phase protein ${ }^{10}$. If you look at the normal function of Hemoglobin it facilitates oxygen $\left(\mathrm{O}_{2}\right)$ and carbon dioxide $\left(\mathrm{CO}_{2}\right)$ transport. It caries and inactivates nitric oxide (NO) and also play the role of a buffer ${ }^{11}$. Hemoglobin in the blood is mainly responsible for stabilizing the oxygen pressure in the tissues 12 . Therefore quantitative and/or qualitative reduction in $\mathrm{Hb}$, may adversely affect the normal functions. Iron is principally required for haemoglobin synthesis. ${ }^{13}$ Intestinal iron absorption is related to erythropoietic requirements, although the regulatory mechanism(s) remain unknown. The usual source of iron in the lung is serum iron which is derived from catabolised erythrocytes and absorbed iron ${ }^{13}$. Probably it may be the reason for low hemoglobin level found to be as a serious risk factor for developing ALRTI. Further studies including other risk factors like low birth weight, lack of breast feeding, severe malnutrition, smoke, cooking fuel etc along with low hemoglobin should be considred as future perspective.

\section{Conclusion}

To conclude $\mathrm{Hb}$ was a risk factor for LRTI $(p<0.001)$. Iron deficiency anemia was the main cause detected. Anemia was responsible for pneumonia more than bronchilitis. Iron supplementation in age group 1 month to 5 years may reduce the incidence of LRTI and prevention of anemia, due to whatever etiology is also essential. The limitation of this study is that other variables were not considered in this study. It is difficult to correlate the one point prevalence of pneumonia with anaemia as the control group could present with pneumonia within another few months. Only way to see is to follow a group of children with normal and low haemoglobin over a period of time for an episode of pneumonia.

Acknowledgements: We thank all the children who had participated in this study. A special thanks to Dr. Praveen shrestha who had helped with data collecton.

\section{Funding: None}

\section{Conflict of Interest: None}

\section{References}

1. DeMaeyer EH, Adiels - Tegman M. The prevalence of anemia in the world. World Health Statistics $1985,38,302-316$.

2. Wald ER. Recurrent and non Resolving Pneumonia in 20 children. Sem Resp Infect 1993; 8: 46-58.

3. Michael A.Pesce. Reference Ranges for Laboratory Tests and procedures. In Richard E. Behrman, Robert Kleigman, Hal B Jenson, ed. Nelson Text Book of Pediatrics. 18th ed. Philadelphia; Saunders, 2008: 2944.

4. Forfar \& Arneil. Text Book of Pediatrrics $5^{\text {th }}$ Edition 1998; Campbell A.G.M. \& Mclntosh N, BPC Wheatons Ltd; Exeter; 1939.

5. Rasmussen Z,Pio A, Enarson P. Case Management of Childhood Pneumonia in Developing Countries: Relevant Research and Current Initiatives. Int J Tuber Lung Dis 2000:4;807-827

6. Behrman S. Epidemiology of Acute Respiratory Infection in Children of Developing Countries. Rev Infect Dis 1991: (suppl): S454-S462.

7. Ramakrishnan K, Harish PS. Hemoglobin Level as a Risk Factor for Lower Respiratory Tract Infections. Indian J Pediatr. 2006:73:10:881-883.

8. Bhaskaran P, Madhavan Nair K, Balakrishnan N. Serum transferrin receptors in children with respiratory infections. Eur J Nutr. 2003; 57: 75-80.

9. De-Silva A, Atukorola S, Weerasinghel. Iron supplementation improves iron status and reduces morbidity in childrenwith or with out URTI. Am J Clin Nutr 2003; 77: 234-241. 
10. Ryan TP, Krzesicki RF, Blakeman DP, et al. Pulmonary Ferritin: Differential Effects of Hyperoxic Lung Injury on Subunit mRNA Levels. Free Radic Biol Med 1997;22:901-908

11. William F Ganong. Gas transport between the lungs and the tissues. Review of Medical Physiology. 22nd ed. New York; Mc Graw-Hill, 2005: 666-669
12. Guyton \& Hall. Effect of hemoglobin to 'Buffer' the tissue PO2. Text Book of Medical Physiology. 11th ed. Philadelphia; Saunders, 2006: 507-508.

13. Fernando Mateos, Jeremy H Brock, José Luis Pérez-Arellanoa. Iron metabolism in the Lower Respiratory Tract. Thorax. 1998; 53:594-600. 